\title{
Exploring an approximation for the homogeneous freezing temperature of water droplets
}

\author{
Kuan-Ting $O$ and Robert Wood \\ University of Washington, Department of Atmospheric Sciences, Seattle, WA, USA \\ Correspondence to: Kuan-Ting O (ktoandy@u.washington.edu)
}

Received: 31 October 2015 - Published in Atmos. Chem. Phys. Discuss.: 12 November 2015

Revised: 20 February 2016 - Accepted: 23 May 2016 - Published: 10 June 2016

\begin{abstract}
In this work, based on the well-known formulae of classical nucleation theory (CNT), the temperature $T_{N_{\mathrm{c}}=1}$ at which the mean number of critical embryos inside a droplet is unity is derived from the Boltzmann distribution function and explored as an approximation for homogeneous freezing temperature of water droplets. Without including the information of the applied cooling rate $\gamma_{\text {cooling }}$ and the number of observed droplets $N_{\text {total_droplets }}$ in the calculation, the approximation $T_{N_{\mathrm{c}}=1}$ is able to reproduce the dependence of homogeneous freezing temperature on drop size $V$ and water activity $a_{\mathrm{w}}$ of aqueous drops observed in a wide range of experimental studies for droplet diameter $>10 \mu \mathrm{m}$ and $a_{\mathrm{w}}>0.85$, suggesting the effect of $\gamma_{\text {cooling }}$ and $N_{\text {total_droplets }}$ may be secondary compared to the effect of $V$ and $a_{\mathrm{w}}$ on homogeneous freezing temperatures in these size and water activity ranges under realistic atmospheric conditions. We use the $T_{N_{\mathrm{c}}=1}$ approximation to argue that the distribution of homogeneous freezing temperatures observed in the experiments may be partly explained by the spread in the size distribution of droplets used in the particular experiment. It thus appears that the simplicity of this approximation makes it potentially useful for predicting homogeneous freezing temperatures of water droplets in the atmosphere.
\end{abstract}

\section{Introduction}

Since the summary article of McDonald (1953), it has been widely observed that ice nucleation of water droplets does not occur at the ice melting temperature (e.g., $273.15 \mathrm{~K}$ at $1 \mathrm{~atm}$ ), and liquid water is frequently observed in clouds as cold as to $238 \mathrm{~K}$ (Rosenfeld and Woodley, 2000; Hu et al., 2010). Laboratory observations of homogeneous ice nucle- ation in pure water generally show that all droplets do not freeze at exactly the same temperature, and that the fraction of droplets that freeze in a given time is a function of temperature and time (hereafter we refer to this type of experiment as a fraction experiment) (e.g., Bigg, 1953; Carte, 1956; Broto and Clausse, 1976; Earle et al., 2010; Riechers et al., 2013). Here, experimental data of the freezing temperatures of pure water droplets from 15 independent studies over the past 60 years are collected (Fig. 1 and Table 1), showing a clear dependence of freezing temperature upon drop volume across different experiments. Over the investigated size interval (1-1000 $\mu \mathrm{m}$ diameter), observed freezing temperatures range from 232 to $240 \mathrm{~K}$. The range of freezing temperatures and the volume dependence in Fig. 1 are consistent with the experimental data reviewed in Pruppacher (1995).

On the other hand, solutes, at sufficiently high concentrations, can suppress the homogeneous freezing temperature of water droplets. Koop et al. (2000) showed that the depression of freezing temperature strongly depends on the water activity $a_{\mathrm{w}}$ of the solution droplet, which has been confirmed in several independent experimental studies (e.g., Knopf and Lopez, 2009; Knopf and Rigg, 2011). In this paper, two aforementioned features of homogeneous ice nucleation observed in the experimental data are examined - (1) the volume and water activity dependence of homogeneous freezing temperatures of water droplets $T_{\mathrm{f}}\left(V, a_{\mathrm{w}}\right)$ and (2) the distribution of homogeneous freezing temperatures observed in fraction experiments $f\left(T_{\mathrm{f}}\right)$. In this paper, we describe only volume-based nucleation and do not include the droplet surface effects on homogeneous ice nucleation as there remains considerable uncertainty about the importance of surface nucleation (Kay et al., 2003; Duft and Leisner, 2004). Unified explanations of the observed dependencies of the homoge- 
Table 1. Information regarding the details of the homogeneous ice nucleation experiments used in the comparison, including the size, the freezing temperature, and the cooling rate and uncertainty of the experiments.

\begin{tabular}{|c|c|c|c|c|c|c|}
\hline References & $\begin{array}{r}\text { Diameter } \\
(\mu \mathrm{m})\end{array}$ & $\begin{array}{r}T_{\mathrm{f}} \\
(\mathrm{K})\end{array}$ & $\begin{array}{r}\text { Diameter } \\
\text { range }(\mu \mathrm{m})\end{array}$ & $\begin{array}{l}\text { Range of freezing } \\
\text { temperatures }(\mathrm{K})\end{array}$ & $\begin{array}{r}\text { Cooling } \\
\text { rate }\end{array}$ & $\begin{array}{r}\text { Uncertainty } \\
(\mathrm{K})\end{array}$ \\
\hline Pound et al. (1953) & $30^{+}$ & $233.15^{a}$ & $10-50$ & $231.15-235.15$ & $\mathrm{n} / \mathrm{a}$ & $\mathrm{n} / \mathrm{a}$ \\
\hline Mossop (1955) & $530^{+}$ & $238.65^{\mathrm{a}}$ & $220-840$ & $238.65-242.15$ & $0.5 \mathrm{~K} \mathrm{~min}^{-1}$ & 0.2 \\
\hline \multirow[t]{16}{*}{ Carte (1956) } & $15^{+}$ & $236.25^{\mathrm{a}}$ & $10-20$ & $235.15-237.15$ & $1 \mathrm{~K}_{\min ^{-1}}$ & 0.2 \\
\hline & $231.3^{\mathrm{n}}$ & $238.45^{b}$ & $\mathrm{n} / \mathrm{a}$ & $\mathrm{n} / \mathrm{a}$ & $0.5 \mathrm{~K} \mathrm{~min}^{-1}$ & 0.2 \\
\hline & $279.4^{\mathrm{n}}$ & $238.55^{\mathrm{b}}$ & $\mathrm{n} / \mathrm{a}$ & $\mathrm{n} / \mathrm{a}$ & $0.5 \mathrm{~K} \mathrm{~min}^{-1}$ & 0.2 \\
\hline & $292.9^{n}$ & $238.35^{\mathrm{b}}$ & $\mathrm{n} / \mathrm{a}$ & $\mathrm{n} / \mathrm{a}$ & $0.5 \mathrm{~K} \mathrm{~min}^{-1}$ & 0.2 \\
\hline & $321.9^{n}$ & $238.45^{b}$ & $\mathrm{n} / \mathrm{a}$ & $\mathrm{n} / \mathrm{a}$ & $0.5 \mathrm{~K} \mathrm{~min}^{-1}$ & 0.2 \\
\hline & $362.2^{\mathrm{n}}$ & $238.55^{b}$ & $\mathrm{n} / \mathrm{a}$ & $\mathrm{n} / \mathrm{a}$ & $0.5 \mathrm{~K} \mathrm{~min}^{-1}$ & 0.2 \\
\hline & $427.3^{\mathrm{n}}$ & $238.65^{b}$ & $\mathrm{n} / \mathrm{a}$ & $\mathrm{n} / \mathrm{a}$ & $0.5 \mathrm{Kmin}^{-1}$ & 0.2 \\
\hline & $469.7^{\mathrm{n}}$ & $238.55^{\mathrm{b}}$ & $\mathrm{n} / \mathrm{a}$ & $\mathrm{n} / \mathrm{a}$ & $0.5 \mathrm{~K} \mathrm{~min}^{-1}$ & 0.2 \\
\hline & $498.2^{\mathrm{n}}$ & $238.95^{b}$ & $\mathrm{n} / \mathrm{a}$ & $\mathrm{n} / \mathrm{a}$ & $0.5 \mathrm{~K} \mathrm{~min}^{-1}$ & 0.2 \\
\hline & $567.3^{\mathrm{n}}$ & $238.95^{b}$ & $\mathrm{n} / \mathrm{a}$ & $\mathrm{n} / \mathrm{a}$ & $0.5 \mathrm{~K} \mathrm{~min}^{-1}$ & 0.2 \\
\hline & $623.6^{\mathrm{n}}$ & $238.85^{b}$ & $\mathrm{n} / \mathrm{a}$ & $\mathrm{n} / \mathrm{a}$ & $0.5 \mathrm{~K} \mathrm{~min}^{-1}$ & 0.2 \\
\hline & $718.5^{\mathrm{n}}$ & $238.85^{\mathrm{b}}$ & $\mathrm{n} / \mathrm{a}$ & $\mathrm{n} / \mathrm{a}$ & $0.5 \mathrm{~K} \mathrm{~min}^{-1}$ & 0.2 \\
\hline & $818.1^{\mathrm{n}}$ & $238.95^{\mathrm{b}}$ & $\mathrm{n} / \mathrm{a}$ & $\mathrm{n} / \mathrm{a}$ & $0.5 \mathrm{~K} \mathrm{~min}^{-1}$ & 0.2 \\
\hline & $965.2^{\mathrm{n}}$ & $239.15^{b}$ & $\mathrm{n} / \mathrm{a}$ & $\mathrm{n} / \mathrm{a}$ & $0.5 \mathrm{~K} \mathrm{~min}^{-1}$ & 0.2 \\
\hline & $1179.8^{n}$ & $239.45^{b}$ & $\mathrm{n} / \mathrm{a}$ & $\mathrm{n} / \mathrm{a}$ & $0.5 \mathrm{~K} \mathrm{~min}^{-1}$ & 0.2 \\
\hline & $1408.4^{\mathrm{n}}$ & $239.65^{b}$ & $\mathrm{n} / \mathrm{a}$ & $\mathrm{n} / \mathrm{a}$ & $0.5 \mathrm{~K} \mathrm{~min}^{-1}$ & 0.2 \\
\hline \multirow[t]{6}{*}{ Langham and Mason (1958) } & $66.1^{\mathrm{n}}$ & $237.35^{\mathrm{a}}$ & $\mathrm{n} / \mathrm{a}$ & $\mathrm{n} / \mathrm{a}$ & $0.33 \mathrm{Kmin}^{-1}$ & $\mathrm{n} / \mathrm{a}$ \\
\hline & $92.3^{\mathrm{n}}$ & $237.65^{\mathrm{a}}$ & $\mathrm{n} / \mathrm{a}$ & $\mathrm{n} / \mathrm{a}$ & $0.33 \mathrm{Kmin}^{-1}$ & $\mathrm{n} / \mathrm{a}$ \\
\hline & $115.3^{\mathrm{n}}$ & $238.15^{\mathrm{a}}$ & $\mathrm{n} / \mathrm{a}$ & $\mathrm{n} / \mathrm{a}$ & $0.33 \mathrm{Kmin}^{-1}$ & $\mathrm{n} / \mathrm{a}$ \\
\hline & $144^{\mathrm{n}}$ & $238.25^{\mathrm{a}}$ & $\mathrm{n} / \mathrm{a}$ & $\mathrm{n} / \mathrm{a}$ & $0.33 \mathrm{Kmin}^{-1}$ & $\mathrm{n} / \mathrm{a}$ \\
\hline & $171.8^{\mathrm{n}}$ & $238.15^{\mathrm{a}}$ & $\mathrm{n} / \mathrm{a}$ & $\mathrm{n} / \mathrm{a}$ & $0.33 \mathrm{Kmin}^{-1}$ & $\mathrm{n} / \mathrm{a}$ \\
\hline & $270.5^{\mathrm{n}}$ & $238.55^{\mathrm{a}}$ & $\mathrm{n} / \mathrm{a}$ & $\mathrm{n} / \mathrm{a}$ & $0.33 \mathrm{~K} \mathrm{~min}^{-1}$ & $\mathrm{n} / \mathrm{a}$ \\
\hline \multirow[t]{2}{*}{ Hoffer (1961) } & $110^{+}$ & $236.55^{\mathrm{a}}$ & $100-120$ & $235.65-238.15$ & $1 \mathrm{~K} \mathrm{~min}^{-1}$ & 0.5 \\
\hline & $130^{+}$ & $237.25^{\mathrm{a}}$ & $125-145$ & $235.65-238.15$ & $1 \mathrm{Kmin}^{-1}$ & 0.5 \\
\hline \multirow[t]{14}{*}{ Kuhns and Mason (1968) } & $1^{\mathrm{n}}$ & $233.05^{\mathrm{a}}$ & $\mathrm{n} / \mathrm{a}$ & $\mathrm{n} / \mathrm{a}$ & $6 \mathrm{~K} \mathrm{~min}^{-1}$ & 0.1 \\
\hline & $5^{\mathrm{n}}$ & $234.65^{\mathrm{a}}$ & $\mathrm{n} / \mathrm{a}$ & $\mathrm{n} / \mathrm{a}$ & $6 \mathrm{~K} \mathrm{~min}^{-1}$ & 0.1 \\
\hline & $8^{\mathrm{n}}$ & $235.15^{\mathrm{a}}$ & $\mathrm{n} / \mathrm{a}$ & $\mathrm{n} / \mathrm{a}$ & $6 \mathrm{~K} \mathrm{~min}^{-1}$ & 0.1 \\
\hline & $10^{\mathrm{n}}$ & $235.45^{\mathrm{a}}$ & $\mathrm{n} / \mathrm{a}$ & $\mathrm{n} / \mathrm{a}$ & $6 \mathrm{Kmin}^{-1}$ & 0.1 \\
\hline & $20^{\mathrm{n}}$ & $236.15^{\mathrm{a}}$ & $\mathrm{n} / \mathrm{a}$ & $\mathrm{n} / \mathrm{a}$ & $6 \mathrm{~K}_{\min ^{-1}}$ & 0.1 \\
\hline & $30^{\mathrm{n}}$ & $236.75^{\mathrm{a}}$ & $\mathrm{n} / \mathrm{a}$ & $\mathrm{n} / \mathrm{a}$ & $6 \mathrm{~K}_{\min ^{-1}}$ & 0.1 \\
\hline & $40^{\mathrm{n}}$ & $237.05^{\mathrm{a}}$ & $\mathrm{n} / \mathrm{a}$ & $\mathrm{n} / \mathrm{a}$ & $6 \mathrm{~K} \mathrm{~min}^{-1}$ & 0.1 \\
\hline & $50^{\mathrm{n}}$ & $237.25^{\mathrm{a}}$ & $\mathrm{n} / \mathrm{a}$ & $\mathrm{n} / \mathrm{a}$ & $6 \mathrm{~K}_{\min ^{-1}}$ & 0.1 \\
\hline & $60^{\mathrm{n}}$ & $237.35^{\mathrm{a}}$ & $\mathrm{n} / \mathrm{a}$ & $\mathrm{n} / \mathrm{a}$ & $6 \mathrm{~K} \mathrm{~min}^{-1}$ & 0.1 \\
\hline & $70^{\mathrm{n}}$ & $237.45^{\mathrm{a}}$ & $\mathrm{n} / \mathrm{a}$ & $\mathrm{n} / \mathrm{a}$ & $6 \mathrm{~K}_{\min ^{-1}}$ & 0.1 \\
\hline & $80^{\mathrm{n}}$ & $237.55^{\mathrm{a}}$ & $\mathrm{n} / \mathrm{a}$ & $\mathrm{n} / \mathrm{a}$ & $6 \mathrm{~K}_{\min ^{-1}}$ & 0.1 \\
\hline & $90^{\mathrm{n}}$ & $237.65^{\mathrm{a}}$ & $\mathrm{n} / \mathrm{a}$ & $\mathrm{n} / \mathrm{a}$ & $6 \mathrm{~K}_{\min ^{-1}}$ & 0.1 \\
\hline & $100^{\mathrm{n}}$ & $237.65^{\mathrm{a}}$ & $\mathrm{n} / \mathrm{a}$ & $\mathrm{n} / \mathrm{a}$ & $6 \mathrm{~K}_{\min }^{-1}$ & 0.1 \\
\hline & $120^{\mathrm{n}}$ & $237.65^{a}$ & $\mathrm{n} / \mathrm{a}$ & $\mathrm{n} / \mathrm{a}$ & $6 \mathrm{Kmin}^{-1}$ & 0.1 \\
\hline Broto and Clausse (1976) & $3^{\mathrm{n}}$ & $234.35^{\mathrm{a}}$ & $\mathrm{n} / \mathrm{a}$ & $\mathrm{n} / \mathrm{a}$ & $1.25 \mathrm{~K} \mathrm{~min}^{-1}$ & 0.5 \\
\hline Cziczo and Abbatt (1999) & $0.35^{\mathrm{n}}$ & $234.15^{\mathrm{d}}$ & $\mathrm{n} / \mathrm{a}$ & $\mathrm{n} / \mathrm{a}$ & $\mathrm{n} / \mathrm{a}$ & $\mathrm{n} / \mathrm{a}$ \\
\hline Bertram et al. (2000) & $8.3^{+}$ & $235^{\mathrm{a}}$ & $5.6-11.0$ & $\mathrm{n} / \mathrm{a}$ & $10 \mathrm{Kmin}^{-1}$ & 1.5 \\
\hline Prenni et al. (2001) & $0.6^{+}$ & $234.95^{d}$ & $\mathrm{n} / \mathrm{a}$ & $\mathrm{n} / \mathrm{a}$ & $1 \mathrm{~K}_{\text {increment }}{ }^{-1}$ & 0.2 \\
\hline Larson and Swanson (2006) & $40^{+}$ & $237.15^{\mathrm{a}}$ & $30-50$ & $\mathrm{n} / \mathrm{a}$ & $\mathrm{n} / \mathrm{a}$ & $\mathrm{n} / \mathrm{a}$ \\
\hline Stan et al. (2009) & $80^{\mathrm{n}}$ & $236.25^{\mathrm{a}}$ & $\mathrm{n} / \mathrm{a}$ & $235.35-237.15$ & 2 to $100 \mathrm{~K} \mathrm{~s}^{-1}$ & 0.21 \\
\hline
\end{tabular}


Table 1. Continued.

\begin{tabular}{|c|c|c|c|c|c|c|}
\hline References & $\begin{array}{r}\text { Diameter } \\
(\mu \mathrm{m})\end{array}$ & $\begin{array}{r}T_{\mathrm{f}} \\
(\mathrm{K})\end{array}$ & $\begin{array}{r}\text { Diameter } \\
\text { range }(\mu \mathrm{m})\end{array}$ & $\begin{array}{r}\text { Range of freezing } \\
\text { temperatures }(\mathrm{K})\end{array}$ & $\begin{array}{r}\text { Cooling } \\
\text { rate }\end{array}$ & $\begin{array}{r}\text { Uncertainty } \\
(\mathrm{K})\end{array}$ \\
\hline \multirow[t]{3}{*}{ Earle et al. (2010) } & $2^{+}$ & $236.35^{\mathrm{a}}$ & $0.8-4$ & $236-236.75$ & $\mathrm{n} / \mathrm{a}$ & $\mathrm{n} / \mathrm{a}$ \\
\hline & $3.4^{+}$ & $236.35^{\mathrm{a}}$ & $1.2-10$ & $236-236.75$ & $\mathrm{n} / \mathrm{a}$ & $\mathrm{n} / \mathrm{a}$ \\
\hline & $5.8^{+}$ & $236.15^{\mathrm{a}}$ & $2-14$ & $235.5-236.75$ & $\mathrm{n} / \mathrm{a}$ & $\mathrm{n} / \mathrm{a}$ \\
\hline \multirow[t]{4}{*}{ Murray et al. (2010) } & $25^{+}$ & $236.25^{\mathrm{a}}$ & $10-40$ & $235.9-236.7$ & $2.5 \mathrm{~K} \mathrm{~min}^{-1}$ & 0.6 \\
\hline & $25^{+}$ & $236.05^{\mathrm{a}}$ & $10-40$ & $234.75-237.75$ & $5 \mathrm{~K} \mathrm{~min}^{-1}$ & 0.6 \\
\hline & $25^{+}$ & $235.75^{\mathrm{a}}$ & $10-40$ & $236.45-237.75$ & $7.5 \mathrm{~K} \mathrm{~min}^{-1}$ & 0.6 \\
\hline & $25^{+}$ & $235.51^{\mathrm{a}}$ & $10-40$ & $234.45-237.75$ & $10 \mathrm{Kmin}^{-1}$ & 0.6 \\
\hline \multirow[t]{5}{*}{ Riechers et al. (2013) } & $53^{\mathrm{m}}$ & $236.65^{\mathrm{c}}$ & $35-71$ & $236.55-237.44$ & $1 \mathrm{~K}_{\min ^{-1}}$ & 0.3 \\
\hline & $63^{\mathrm{m}}$ & $236.65^{\mathrm{c}}$ & $33-93$ & 236.49-237.5 & $1 \mathrm{~K} \mathrm{~min}^{-1}$ & 0.3 \\
\hline & $82^{\mathrm{m}}$ & $236.85^{\mathrm{c}}$ & $58-106$ & $236.67-237.63$ & $1 \mathrm{Kmin}^{-1}$ & 0.3 \\
\hline & $85^{\mathrm{m}}$ & $237.15^{\mathrm{c}}$ & $67-103$ & $236.93-237.77$ & $1 \mathrm{~K} \mathrm{~min}^{-1}$ & 0.3 \\
\hline & $96^{\mathrm{m}}$ & $237.35^{\mathrm{c}}$ & $63-129$ & 236.89-237.91 & $1 \mathrm{Kmin}^{-1}$ & 0.3 \\
\hline
\end{tabular}

Homogeneous freezing temperature $T_{\mathrm{f}}$ : ${ }^{\mathrm{a}}$ Freezing temperature when half of the water droplets are frozen $T_{50 \%} ;{ }^{\mathrm{b}}$ freezing temperature when $95 \%$ of the water droplets are frozen $T_{95} \% ;{ }^{\mathrm{c}}$ freezing temperature when most of the droplets are frozen (peak signal) $T_{\mathrm{Mode}}$; and ${ }^{\mathrm{d}}$ not defined or provided by the experiments. Diameter of water droplets used in the experiments: ${ }^{+}$median size; ${ }^{m}$ mean size; and ${ }^{\mathrm{n}}$ not provided by the experiments.

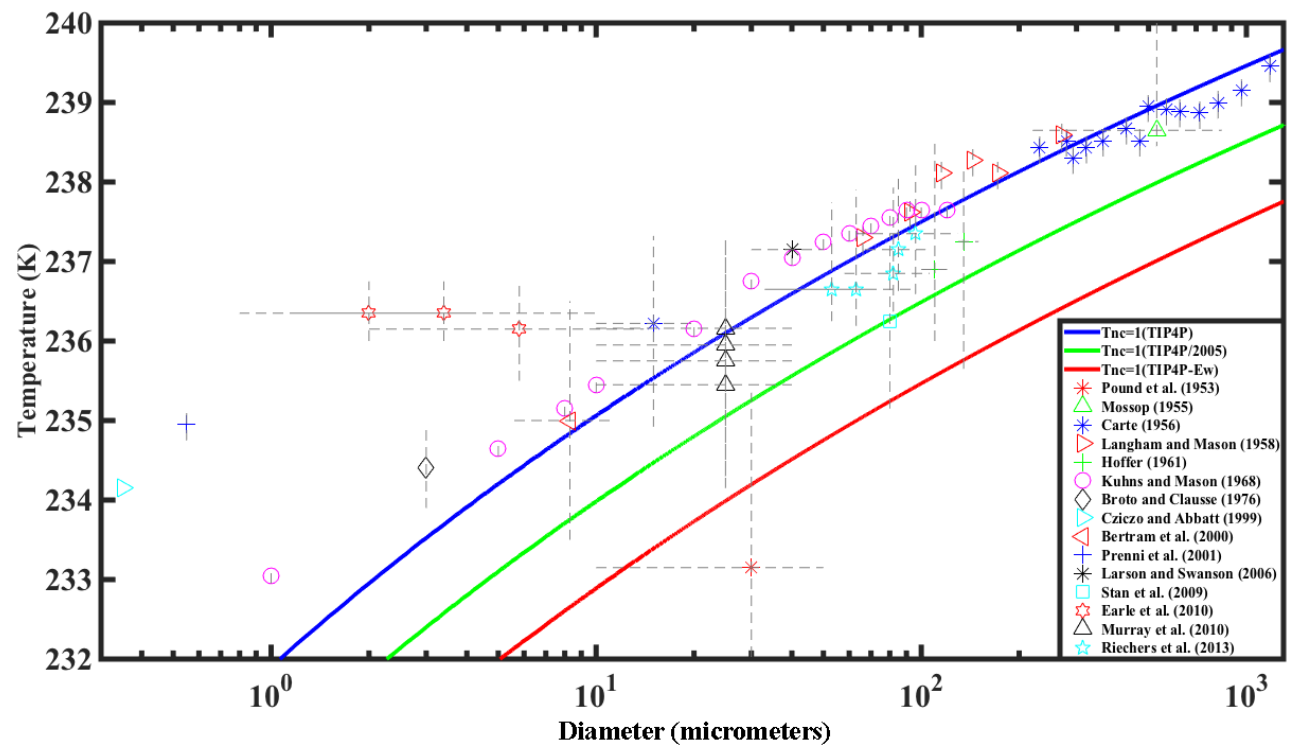

Figure 1. Freezing temperatures of pure water droplets: comparison between the approximations $T_{N_{\mathrm{c}}=1}\left(V, a_{\mathrm{w}}=1\right)$ and the collected experimental data. Experimental data: the uncertainties and ranges of the drop size and the freezing temperatures are presented by the dotted lines if information is provided by the studies (details in Table 1). The approximations $T_{N_{\mathrm{c}}=1}\left(V, a_{\mathrm{w}}=1\right)$ : blue line $-\sigma_{\mathrm{i} / \mathrm{w}, \mathrm{e}}$ from the TIP4P model; green line $-\sigma_{\mathrm{i} / \mathrm{w}, \mathrm{e}}$ from the TIP4P/2005 model; and red line $-\sigma_{\mathrm{i} / \mathrm{w}, \mathrm{e}}$ from the TIP4P-Ew model. See Sect. 2 for the definition and calculation of $T_{N_{\mathrm{c}}=1}$.

neous freezing temperature on droplet size and water activity have been proposed by several studies based on different theoretical frameworks such as ice nucleation rate $J$ and density fluctuation (e.g., Pruppacher, 1995; Baker and Baker, 2004; Khvorostyanov and Curry, 2009; Barahona, 2014). In our study, based on a cornerstone of classical nucleation theory (CNT), namely that a critical embryo existing in a droplet triggers ice crystal formation, we explore a simple approxi- mation for the homogeneous freezing temperature and seek a simpler parameterization to describe homogeneous ice nucleation process in the atmosphere. Section 2 describes the approximation, Sect. 3 gives the comparisons between the theoretical estimates and the experimental data, Sect. 4 is the discussion, and Sect. 5 is the summary. 


\section{Background}

\subsection{The approximation $T_{N_{\mathrm{c}}=1}\left(V, a_{\mathrm{w}}\right)$}

According to CNT, the formation of a critical embryo inside a droplet can trigger the freezing process in the droplet. The critical embryo, defined as the $i$-mers having the highest formation energy, is formed by the critical fluctuation in orientation of hydrogen bonds (e.g., density fluctuation) (Baker and Baker, 2004), which is large enough to provide the formation energy of the critical embryo $\Delta F_{\mathrm{c}}\left(T, a_{\mathrm{w}}\right)$ and remove metastability of supercooled water. The probability of occurrence of the critical fluctuation is $\exp \left(\frac{-\Delta F_{\mathrm{c}}\left(T, a_{\mathrm{w}}\right)}{k_{\mathrm{B}} T}\right)$ (Landau and Lifshitz, 1969, p. 472-473; Pruppacher and Klett, 1997), and thus the mean number of the critical embryos inside a water droplet in thermal equilibrium can be predicted by a Boltzmann distribution (Landau and Liftshitz, 1969, p. 107; Vali, 1999),

$N_{\mathrm{c} \_ \text {mean }}\left(V, a_{\mathrm{w}}, T\right)=V \rho \exp \left(\frac{-\Delta F_{\mathrm{c}}\left(T, a_{\mathrm{w}}\right)}{k_{\mathrm{B}} T}\right)$,

where $V$ is the volume of the droplet, $\rho$ is the number density of water molecules, $k_{\mathrm{B}}$ is Boltzmann's constant, $T$ is the temperature of the droplet, and $\Delta F_{\mathrm{c}}\left(T, a_{\mathrm{w}}\right)$ is the formation energy of the critical embryo in the droplet with water activity $a_{\mathrm{w}}$ at $T$, which will be discussed in detail in Sect. 2.2. The Boltzmann distribution form of the critical embryo is derived from the partitioning function of the grand canonical ensemble, and it should be noted that the derived particle number of the Boltzmann distribution function is not a "constant" but a "mean" number (detailed derivation and explanations can be found in Landau and Liftshitz, 1969, p. 107, and Sadovskii, 2012, Chapter 3.1).

The total freezing time $\tau_{\text {freezing }}$ of a water droplet can be split conceptually into three stages - (1) $\tau_{\text {meta_remove }}\left(\sim \frac{1}{J}\right)$, the time needed for the occurrence of the critical fluctuation; (2) $\tau_{\text {formation, }}$, the time needed to form a critical embryo; and (3) $\tau_{\text {growing, }}$, the growing time for the critical embryo expanding to the whole droplet body. These depend on $V, a_{\mathrm{w}}$ and $T$ of the droplet (Pruppacher and Klett, 1997; Bauerecker et al., 2008). To observe freezing of droplets with volume $V$ and water activity $a_{\mathrm{w}}$ occurring at temperature $T$, the residence time of freezing experiments $\tau_{\text {residence }}$ at $T$ has to be longer than $\tau_{\text {freezing }}\left(V, a_{\mathrm{w}}, T\right)$, resulting in a dependence of the homogeneous freezing temperature on the cooling rate $\gamma_{\text {cooling }}$ of droplets in principle. According to the theoretical estimates (see Pruppacher and Klett, 1997, p. 678), the timescale of $\tau_{\text {formation }}+\tau_{\text {growing }}$ for the size of the droplets investigated here is short compared with the typical residence times in the laboratory studies. Thus, the dominant factor determining the homogeneous freezing temperatures is $\tau_{\text {meta_remove }}$. Because $\tau_{\text {meta_remove }}$ is the time needed for the occurrence of the critical fluctuation among water molecules, $\tau_{\text {meta_remove }}$ is shorter in a larger droplet with more molecules $V \rho$ or at lower temperature when the fluctuation probability $\exp \left(\frac{-\Delta F_{\mathrm{c}}\left(T, a_{\mathrm{w}}\right)}{k_{\mathrm{B}} T}\right)$ is higher; $\tau_{\text {meta_remove }}^{-1} \propto$ $N_{\mathrm{c} \_ \text {mean }}\left(V, a_{\mathrm{w}}, T\right)$. Embryo creation and growth is a stochastic process and $N_{\mathrm{c} \_ \text {mean }}\left(V, a_{\mathrm{w}}, T\right)$ simply expresses the mean state, so there is always a spread of $\tau_{\text {meta remove among }}$ droplets even in an idealized case that all the droplets used in the experiment have exactly the same $V$ and $a_{\mathrm{w}}$ and are at exactly the same temperature $T$. The spread of $\tau_{\text {meta_remove }}$ can be wider when there are more observed droplets $N_{\text {total_droplets, }}$, which in principle can explain the fraction experiments that some droplets with shorter $\tau_{\text {meta_remove }}$ can always be frozen at higher temperature, or in shorter time for droplets at the same temperature even when the droplets have a monodisperse size distribution and exactly the same $a_{\mathrm{w}}$. Hereafter we refer to the distribution of homogeneous freezing temperatures owing to $N_{\text {total_droplets }}$ when all the droplets have exactly same $V$ and $a_{\mathrm{w}}$ as a stochastic feature. Based on the abovementioned principles, the homogenous freezing temperature of water droplets and $\tau_{\text {meta_remove }}$ can each be written as a function of $V, a_{\mathrm{w}}, \gamma_{\text {cooling }}$ and $N_{\text {total_droplets, namely }} T_{\mathrm{f}}\left(V, a_{\mathrm{w}}, \gamma_{\text {cooling }}, N_{\text {total_droplets }}\right)$ and $\tau_{\text {meta_remove }}\left(V, a_{\mathrm{w}}, \gamma_{\text {cooling }}, N_{\text {total_droplets }}\right)$.

Koop et al. (1998) reported that observed homogeneous freezing temperatures do not significantly depend on $\gamma_{\text {cooling }}$ of the droplets for $\gamma_{\text {cooling }}$ smaller than $20 \mathrm{~K} \mathrm{~min}^{-1}$ (corresponding to vertical velocities $33.3 \mathrm{~m} \mathrm{~s}^{-1}$ in clear air). The results of Koop et al. (1998) actually indicate that the slope of $\frac{\partial \tau_{\text {meta }} \text { remove }}{\partial T}$ is very steep at the temperature when the scale of $\tau_{\text {meta_remove }}$ is close to $\tau_{\text {residence }}$ in most practical experiments and realistic atmospheric conditions, resulting in the small dependence of $T_{\mathrm{f}}$ on $\gamma_{\text {cooling }}$ as suggested by Brewer and Palmer (1951). Based on that, in most of the practical freezing experiments and realistic atmospheric conditions $\left(\gamma_{\text {cooling }}<20 \mathrm{~K} \mathrm{~min}^{-1}\right)$, the observed homogeneous freezing temperatures can be considered as a threshold temperature when $\frac{\partial \tau_{\text {meta remove }}}{\partial T} \rightarrow \infty$. In this study, we intend to find this threshold temperature directly from the information given by $N_{\mathrm{c} \_ \text {mean }}\left(V, a_{\mathrm{w}}, T\right)$. The number of critical embryos derived from the Boltzmann distribution is a mean value and does not provide any information regarding freezing time, so it cannot be used to study the dependence of the homogeneous freezing temperature on cooling rate (i.e., time dependence) and number of droplets used in the experiments (i.e., stochastic feature). Nevertheless, since the formation of one critical embryo is required to trigger the ice nucleation process in a droplet, $T_{N_{\mathrm{c}}=1}$ may be a good approximation for the threshold temperature, the temperature at which the mean number of the critical embryos inside a droplet is unity, which can be given by

$N_{\mathrm{c} \_ \text {mean }}=1=V \rho \exp \left(\frac{-\Delta F_{\mathrm{c}}\left(T_{N_{\mathrm{c}}=1}, a_{\mathrm{w}}\right)}{k_{\mathrm{B}} T_{N_{\mathrm{c}}=1}}\right)$.

According to the formula of $\Delta F_{\mathrm{c}}\left(T, a_{\mathrm{w}}\right), T_{N_{\mathrm{c}}=1}$ is determined by $V$ and $a_{\mathrm{w}}$ of the droplet, namely $T_{N_{\mathrm{c}}=1}\left(V, a_{\mathrm{w}}\right)$. 


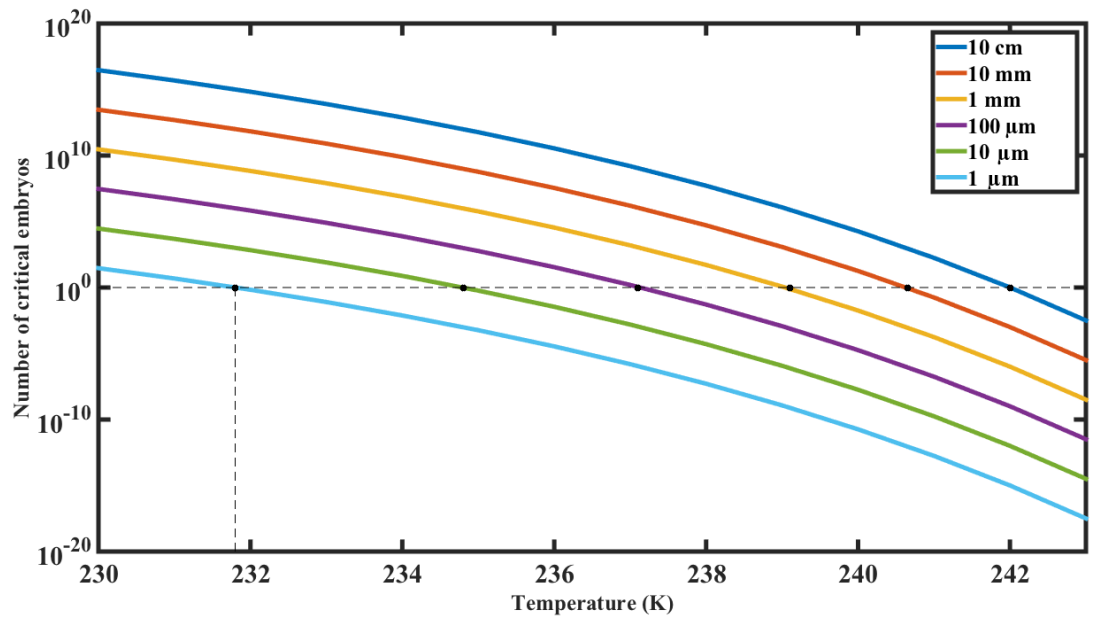

Figure 2. Mean number of critical embryos $N_{\mathrm{c} \_ \text {mean }}$ (by Eq. 1) in a pure water droplet $\left(a_{\mathrm{W}}=1\right)$ with different size (diameter) as a function of temperature. Solid circle: the approximations $T_{N_{\mathrm{c}}=1}\left(V, a_{\mathrm{w}}\right)$ derived by Eq. (2) (using $\sigma_{\mathrm{i} / \mathrm{w}, \mathrm{e}}$ from the TIP4P model).

Figure 2 shows the mean number of critical embryos inside a pure water droplet $\left(a_{\mathrm{w}}=1\right)$ at different temperatures using Eq. (1) (see next section for details of $\Delta F_{\mathrm{c}}\left(T, a_{\mathrm{w}}\right)$ used in the calculation). It indicates that smaller droplets require lower temperatures to reach the state that $N_{\mathrm{c} \_ \text {mean }}=1$, showing the volume dependence of $T_{N_{\mathrm{c}}=1}\left(V, a_{\mathrm{w}}\right)$. Figure 3 shows the mean number of critical embryos inside a solution droplet with different values of water activity. The result indicates that more concentrated solution droplets (lower $a_{\mathrm{w}}$ ) need lower temperature to reach the state that $N_{\mathrm{c}_{-} \text {mean }}=1$. This represents the solution effect on $T_{N_{\mathrm{c}}=1}\left(V, a_{\mathrm{w}}\right)$. The sensitivity of $T_{N_{\mathrm{c}}=1}\left(V, a_{\mathrm{w}}\right)$ to the variation of diameter $\delta d$ and water activity $\delta a_{\mathrm{w}}$ of droplets can be written as

$\delta T_{N_{\mathrm{c}}=1}=\frac{\partial T_{N_{\mathrm{c}}=1}}{\partial a_{\mathrm{w}}} \delta a_{\mathrm{w}}+\frac{\partial T_{N_{\mathrm{c}}=1}}{\partial \log _{10} d} \delta \log _{10} d$,

where $d$ is the diameter of droplet $(\mu \mathrm{m})$. As shown in Fig. 1, the dependence of $T_{N_{\mathrm{c}}=1}$ on $\log _{10} d$ is nearly linear, so the decadal $\log$ is used here to simply derive the linear dependence. The values of $\frac{\partial T_{N_{\mathrm{c}}=1}}{\partial a_{\mathrm{W}}}$ and $\frac{\partial T_{N_{\mathrm{c}}=1}}{\partial \log _{10} d}$ are about 216 and $2.5 \mathrm{~K}$, respectively, over the investigated interval of water activity and drop size, which are derived numerically from Eq. (2).

\subsection{Formation energy of the critical embryo $\Delta F_{\mathrm{c}}\left(T, a_{\mathrm{w}}\right)$}

The formation energy of the critical embryo $\Delta F_{\mathrm{c}}\left(T, a_{\mathrm{w}}\right)$ can be written as

$$
\begin{aligned}
& \Delta F_{\mathrm{c}}=\frac{1}{3} s \sigma_{\mathrm{i} / \mathrm{w}}\left(T, a_{\mathrm{w}}\right) r_{\mathrm{c}}^{2}, \\
& r_{\mathrm{c}}=\frac{2 \sigma_{\mathrm{i} / \mathrm{w}}\left(T, a_{\mathrm{w}}\right) v_{1}^{\text {water }}}{k_{\mathrm{B}} T \ln \left(\frac{e_{\mathrm{sw}} a_{\mathrm{w}}}{e_{\mathrm{si}}}\right)+k_{\mathrm{B}} T \ln \left(a_{\mathrm{w}}\right)},
\end{aligned}
$$

where $\sigma_{\mathrm{i} / \mathrm{w}}\left(T, a_{\mathrm{w}}\right)$ is the interfacial energy between liquid water and solid ice, $s$ is the shape factor of the embryo $(\sim 21$ by assuming the shape is hexagonal prism), $r_{\mathrm{c}}$ is the radius of the critical embryo, $v_{1}^{\text {water }}$ is the volume of single water molecule, $e_{\mathrm{sw}}$ and $e_{\mathrm{si}}$ are the saturation vapor pressures over water and ice, respectively (Murphy and Koop, 2005), and $a_{\mathrm{w}}$ is the water activity of the solution droplet (see detailed derivations of Eq. 4 in Defour and Defay, 1963, and Pruppacher and Klett, 1997). It should be noted that the term $k_{\mathrm{B}} T \ln \left(a_{\mathrm{w}}\right)$ in $r_{\mathrm{c}}$ (Eq. 5) is the entropy of unmixing, which originates from the change in the Gibbs free energy of the bulk solution during freezing and has generally been neglected in the previous theoretical studies (Bourne and Davey, 1976; Black, 2007). Barahona (2014) pointed out that although this term is small for dilute solution, it should not be neglected when applying to high-concentration solution droplets (see Eq. 8 in Barahona, 2014).

The value of interfacial energy between liquid water and solid ice $\sigma_{\mathrm{i} / \mathrm{w}}\left(T, a_{\mathrm{w}}\right)$ is needed for our calculation of Eqs. (4) and (5). As most studies suggest that the temperature dependence of $\sigma_{\mathrm{i} / \mathrm{w}}\left(T, a_{\mathrm{w}}\right)$ should be linear (Ickes et al., 2015), and that increasing the concentration of the solution droplet increases the value of $\sigma_{\mathrm{i} / \mathrm{w}}\left(T, a_{\mathrm{w}}\right)$ (Jones and Chadwick, 1971; Alpert et al., 2011), $\sigma_{\mathrm{i} / \mathrm{w}}\left(T, a_{\mathrm{w}}\right)$ can be written as

$\sigma_{\mathrm{i} / \mathrm{w}}\left(T, a_{\mathrm{w}}\right)=\sigma_{\mathrm{i} / \mathrm{w}, \mathrm{e}}+\frac{\partial \sigma_{\mathrm{i} / \mathrm{w}}}{\partial T}\left(T-T_{0}\right)+\frac{\partial \sigma_{\mathrm{i} / \mathrm{w}}}{\partial a_{\mathrm{w}}}\left(1-a_{\mathrm{w}}\right)$,

where $\sigma_{\mathrm{i} / \mathrm{w}, \mathrm{e}}$ is the interfacial energy at the equilibrium temperature of pure ice water and $T_{0}$ is the equilibrium temperature. The direct measurement of $\sigma_{\mathrm{i} / \mathrm{w}}\left(T, a_{\mathrm{w}}\right)$ is extremely difficult, so most of the estimations are based on combinations of CNT and laboratory measurements of $T_{\mathrm{f}}$ and observed freezing rate to retrieve the values of $\sigma_{\mathrm{i} / \mathrm{w}}\left(T, a_{\mathrm{w}}\right)$ (e.g., Zobrist et al., 2007; Murray et al., 2010). These studies have shown considerable diversity in the reported estima- 


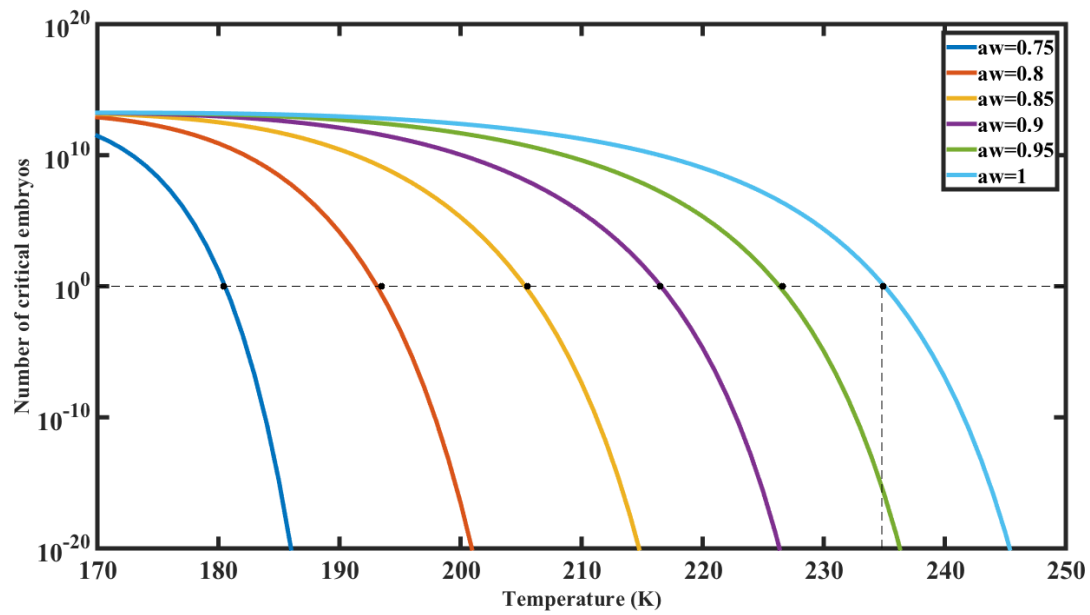

Figure 3. Mean number of critical embryos $N_{\mathrm{c}_{-} \text {mean }}$ (by Eq. 1) in a solution droplet (diameter $\left.=10 \mu \mathrm{m}\right)$ with different water activity as a function of temperature. Solid circle: the approximations $T_{N_{\mathrm{c}}=1}\left(V, a_{\mathrm{W}}\right)$ derived by Eq. (2) (using $\sigma_{\mathrm{i} / \mathrm{w}, \mathrm{e}}$ from TIP4P model).

tions of $\sigma_{\mathrm{i} / \mathrm{w}}\left(T, a_{\mathrm{w}}\right)$ (Ickes et al., 2015). Instead, we use values of $\sigma_{\mathrm{i} / \mathrm{w}, \mathrm{e}}$ and $\frac{\partial \sigma_{\mathrm{i} / \mathrm{w}}}{\partial T}$ derived from a state-of-the-art molecular dynamics model that explicitly simulates the molecular configurations under supercooling conditions. Benet et al. (2014) give values of $\sigma_{\mathrm{i} / \mathrm{w}, \mathrm{e}}$ from the TIP4P $\left(\sigma_{\mathrm{i} / \mathrm{w}, \mathrm{e}}=\right.$ $\left.26.5 \times 10^{-3} \mathrm{~J} \mathrm{~m}^{-2}\right)$, TIP4P/2005 $\left(\sigma_{\mathrm{i} / \mathrm{w}, \mathrm{e}}=27 \times 10^{-3} \mathrm{~J} \mathrm{~m}^{-2}\right)$, and TIP4P-Ew water models $\left(\sigma_{\mathrm{i} / \mathrm{w}, \mathrm{e}}=27.5 \times 10^{-3} \mathrm{~J} \mathrm{~m}^{-2}\right)$, and these three values will all be used in our calculations. According to Ickes et al. (2015), the values of $\sigma_{\mathrm{i} / \mathrm{w}, \mathrm{e}}$ used here are close to the median of all the values derived from the previous studies. Regarding $\frac{\partial \sigma_{\mathrm{i}} / \mathrm{w}}{\partial T}$, Espinosa et al. (2014) provided an average value of $0.25 \times 10^{-3}\left(\mathrm{~J} \mathrm{~m}^{-2} \mathrm{~K}^{-1}\right)$ from three different water molecular models (TIP4P/ICE, TIP4P and TIP4P/2005) down to a supercooling of about $30 \mathrm{~K}$. Regarding $\frac{\partial \sigma_{\mathrm{i} / \mathrm{w}}}{\partial a_{\mathrm{w}}}$, Barahona (2014) proposed a new thermodynamic framework approximating the the interfacial energy between ice and aqueous solution by assuming the interface between solid ice and liquid water is made of liquid molecules trapped by the solid matrix, which gives the relationship between $\sigma_{\mathrm{i} / \mathrm{w}}$ and $a_{\mathrm{w}}$. Based on this approximation, the solution effect on the interfacial energy can be written as

$$
\frac{\partial \sigma_{\mathrm{i} / \mathrm{w}}}{\partial a_{\mathrm{w}}}=-\frac{\Gamma_{\mathrm{w}}^{2} s_{\text {area }} k_{\mathrm{B}} T \frac{1}{a_{\mathrm{w}}}}{\left(36 \pi\left(v_{1}^{\text {water }}\right)^{2}\right)^{\frac{1}{3}}},
$$

where $\Gamma_{\mathrm{w}}$ is the surface excess of water $(\sim 1.46)$ (Spaepen, $1975)$ and $s_{\text {area }}$ is the surface area parameter $\left(\sim 1.105 \mathrm{~mol}^{\frac{2}{3}}\right)$ (see Barahona, 2014, for details). The values of $\sigma_{\mathrm{i} / \mathrm{w}}\left(T, a_{\mathrm{w}}\right)$ estimated from above studies are used to derive the numerical result $T_{N_{\mathrm{c}}=1}\left(V, a_{\mathrm{w}}\right)$ presented here.

\section{Results - comparison between the approximation and the experimental data}

\subsection{Volume and water activity dependence of $T_{\mathrm{f}}\left(V, a_{\mathrm{w}}\right)$}

To test our approximation, we aim to compare the observed $T_{\mathrm{f}}\left(V, a_{\mathrm{w}}\right)$ and $f\left(T_{\mathrm{f}}\right)$ with $T_{N_{\mathrm{c}}=1}\left(V, a_{\mathrm{w}}\right)$ derived using the constraint in Eq. (2). First, $T_{N_{\mathrm{c}}=1}\left(V, a_{\mathrm{w}}=1\right)$ of pure water droplet is derived. Figure 1 shows the comparison between the experimentally determined homogeneous freezing temperatures $T_{\mathrm{f}}\left(V, a_{\mathrm{w}}=1\right)$ (details of the experiments are provided in Table 1) and the approximations $T_{N_{\mathrm{c}}=1}\left(V, a_{\mathrm{w}}=\right.$ 1). For droplet diameters $>10 \mu \mathrm{m}$, the theoretical values of $T_{N_{\mathrm{c}}=1}\left(V, a_{\mathrm{w}}=1\right)$ derived by the value of $\sigma_{\mathrm{i} / \mathrm{w}, \mathrm{e}}$ from TIP4P water model agree very well with most of the experimental data $T_{\mathrm{f}}\left(V, a_{\mathrm{w}}=1\right)$. Using the values of $\sigma_{\mathrm{i} / \mathrm{w}, \mathrm{e}}$ from TIP4P/2005 and TIP4P-Ew leads to a shift downward of about $1-2 \mathrm{~K}$ of $T_{N_{\mathrm{c}}=1}\left(V, a_{\mathrm{w}}=1\right)$. There is one study regarding the time dependence that should be mentioned. The laboratory observation of Murray et al. (2010) (black triangle in Fig. 1) showed that varying of cooling rate from 2.5 to $10 \mathrm{~K} \mathrm{~min}^{-1}$ corresponds to a shift of 0.5 to $1 \mathrm{~K}$ in observed freezing temperatures of pure water droplets, and our best agreement estimates that $T_{N_{\mathrm{c}}=1}\left(V, a_{\mathrm{w}}=1\right)$ can only explain the experimental data with the slowest cooling rate $\left(2.5 \mathrm{~K} \mathrm{~min}^{-1}\right)$. The finding of Murray et al. (2010) will be discussed in Sect. 4. For droplets smaller than $10 \mu \mathrm{m}$ (diameter), there are obvious deviations of observed freezing temperatures among the experimental studies. These studies do not provide enough information regarding $\gamma_{\text {cooling, }}$ $N_{\text {total_droplets }}$ and the spread in drop size, so we cannot evaluate what causes the disparity. We suggest that freezing experiments of pure droplets smaller than $10 \mu \mathrm{m}$ (diameter) need more refinement and should report the potentially important dependencies such as applied cooling rate, size distribution 


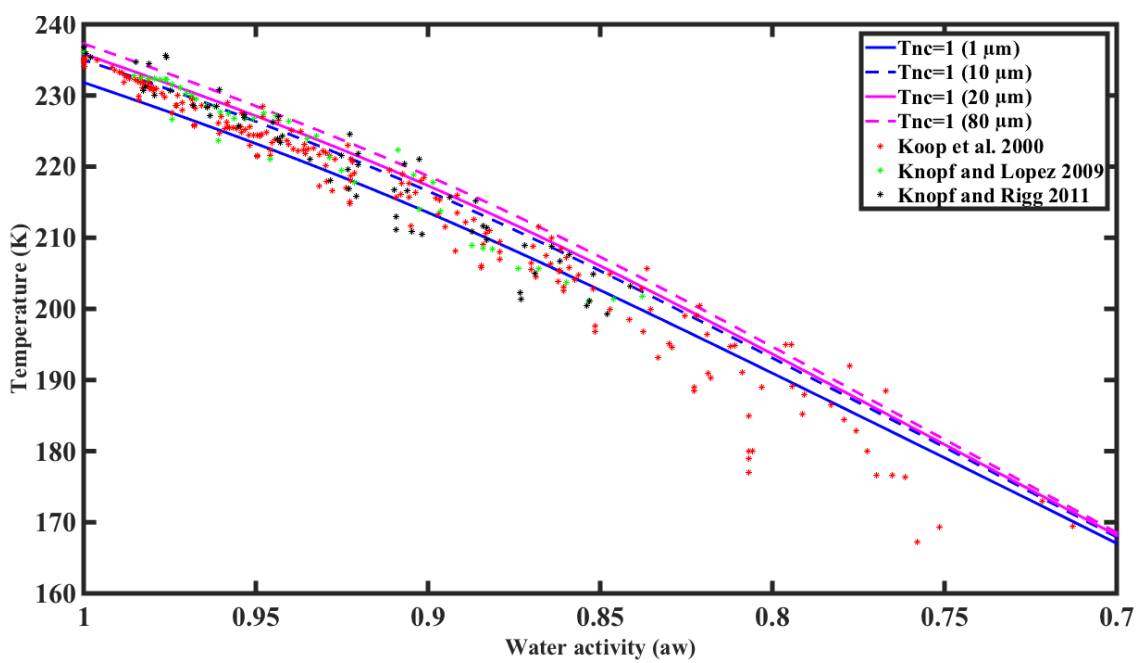

Figure 4. Comparison between the experimental data of freezing temperatures of solution droplets (Koop et al., 2000; Knopf and Lopez, 2009; Knopf and Rigg, 2011) and the approximation $T_{N_{\mathrm{c}}=1}\left(V, a_{\mathrm{W}}\right)$ (using $\sigma_{\mathrm{i} / \mathrm{w}, \mathrm{e}}$ from TIP4P model).

of droplets and number of observed droplets used in experiments.

Second, the solution effect on homogeneous freezing temperature $T_{\mathrm{f}}\left(V, a_{\mathrm{w}}\right)$ is explored by changing the water activity in Eqs. (5) and (6) to derive the approximation $T_{N_{\mathrm{c}}=1}\left(V, a_{\mathrm{w}}\right)$, which will be compared with the experimental data collected in Koop et al. (2000), Knopf and Lopez (2009) and Knopf and Rigg (2011). Droplet sizes used in the collected experimental data range from 1 to $10 \mu \mathrm{m}$ in Koop et al. (2000), from 10 to $80 \mu \mathrm{m}$ in Knopf and Lopez (2009) and from 20 to $80 \mu \mathrm{m}$ in Knopf and Rigg (2011), and these sizes are included to calculate the approximation $T_{N_{\mathrm{c}}=1}\left(V, a_{\mathrm{w}}\right)$. Figure 4 shows the comparison between the experimental data and the approximation $T_{N_{\mathrm{c}}=1}\left(V, a_{\mathrm{w}}\right)$. Without considering the time depen-

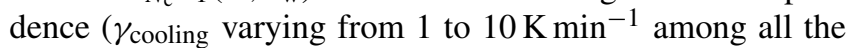
experiments) and the stochastic feature (i.e., $N_{\text {total_droplets }}$ ), the result shows that the approximation $T_{N_{\mathrm{c}}=1}\left(V, a_{\mathrm{w}}\right)$ is in good agreement with the experimental data for $a_{\mathrm{w}}>0.85$. The scattering of the experimental data between the theoretical estimates for $a_{\mathrm{w}}>0.85$ (i.e., $T_{N_{\mathrm{c}}=1}$ for $d=1$ to $80 \mu \mathrm{m}$ ) suggests that the spread of droplet size applied in the experiments may play an important role in the spread of homogeneous freezing temperatures. For the solution droplets with high concentration $\left(a_{\mathrm{w}}<0.85\right)$, the observed freezing temperatures show considerable spread. Abbatt et al. (2006) suggest that the disparity of the experimental data for low $a_{\mathrm{w}}$ can be partly attributed to a variety of heterogeneous process, which can result in the higher observed freezing temperatures. In addition, as suggested by Knopf and Lopez (2009), the deviations at low water activity may be most likely due to our incomplete understanding of $a_{\mathrm{w}}$ for certain aqueous solutions and the corresponding uncertainties. Future experimental study, we suggest, should focus on the freezing process of solution droplets with high solute concentration $\left(a_{\mathrm{w}}<0.85\right)$ to clarify the causes of the disparity.

Regarding the experimental uncertainty, Knopf and Lopez (2009) reported that the value of $a_{\mathrm{w}}$ for supercooled aqueous solutions has the experimental uncertainty $\delta a_{\mathrm{w}}$ of about \pm 0.01 , which can result in the variation in $T_{N_{\mathrm{c}}=1}$ of about $\pm 2 \mathrm{~K}$ based on Eq. (3). Riechers et al. (2013) reported that the size of droplets produced by the microfluidic device used in their experiment has 3 standard deviations (99.7\%) of about 18 to $33 \mu \mathrm{m}$ in diameter, which can cause a variation in $T_{N_{\mathrm{c}}=1}$ of about \pm 0.2 to $\pm 0.5 \mathrm{~K}$ based on Eq. (3). Therefore, the variation in $T_{N_{\mathrm{c}}=1}$ caused by the experimental uncertainties $\delta a_{\mathrm{w}}$ and $\delta d$ can be substantial and should not be neglected. We suggest that future experimental studies should provide detailed information regarding experimental uncertainties $\delta a_{\mathrm{w}}$ and $\delta d$ for the purpose of better constraining the observed freezing temperatures.

\subsection{Fraction of frozen pure water droplets as a function of temperature $f\left(T_{\mathrm{f}}\right)$}

To further examine the application of $T_{N_{\mathrm{c}}=1}\left(V, a_{\mathrm{w}}\right)$ in homogeneous ice nucleation, $T_{N_{\mathrm{c}}=1}\left(V, a_{\mathrm{w}}\right)$ is compared to the experimental data of the fraction experiment of Riechers et al. (2013). According to CNT, the stochastic feature of the ice nucleation process can basically explain the distribution of freezing temperatures observed in the fraction experiments (Pruppacher and Klett, 1997, Eqs. 7-71; Koop et al., 1998; Niedermeier et al., 2011). However, current technology to produce water droplets for such experiments introduces a spread of sizes, and the freezing temperatures show a clear dependence on droplet volume (Fig. 1), so the spread in sizes of water droplets used in the experiments may be important for explaining the distribution $f\left(T_{\mathrm{f}}\right)$. In other words, the size distribution of droplets used in a given experiment 

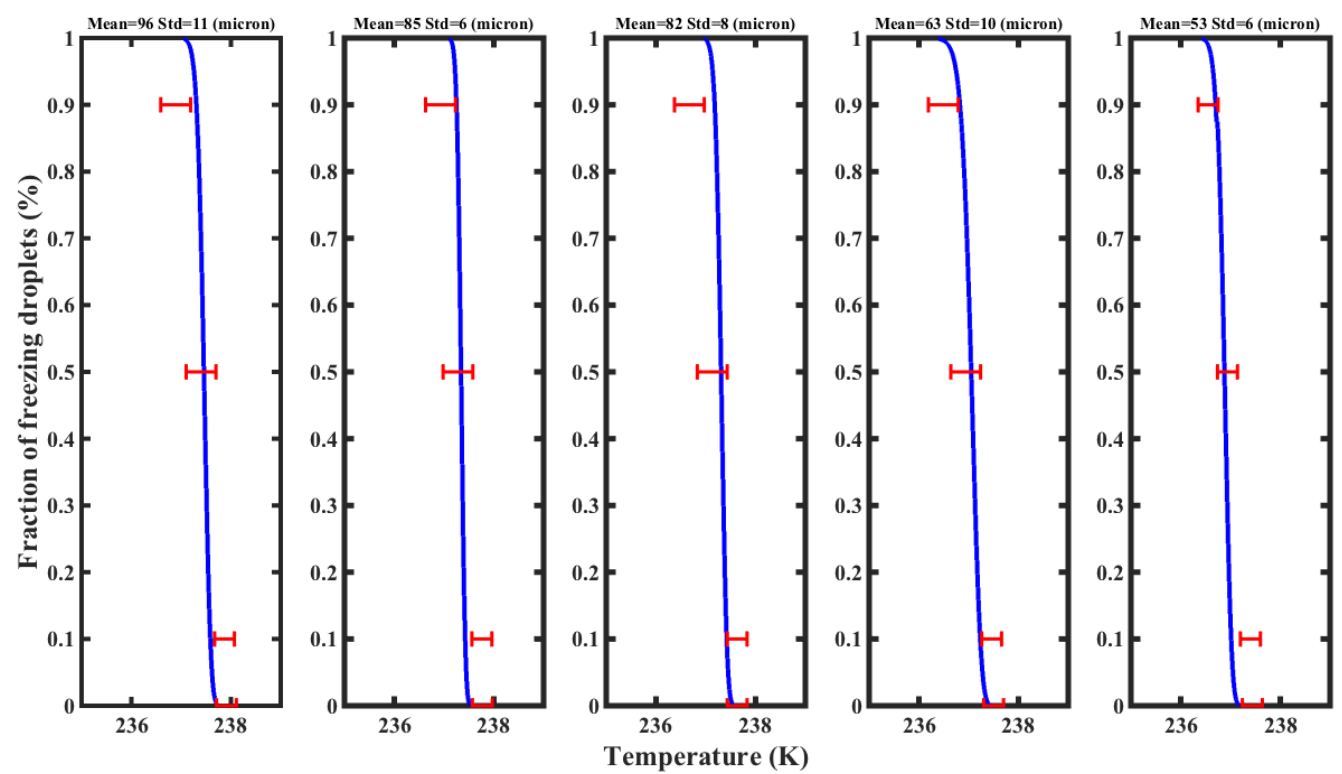

Figure 5. Comparison between the experimental results of the fraction experiment from Riechers et al. (2013) and the theoretical estimates derived here. Red: experimental results with uncertainties from Riechers et al. (2013). Blue: theoretical estimates ( $\sigma_{\mathrm{i} / \mathrm{w}, \mathrm{e}}$ from the TIP4P model).

may be an important factor governing the observed spread of freezing temperatures (i.e., dotted line shown in Fig. 1). To test this, we incorporate the reported droplet size distribution width into the numerical calculation. Unique among such studies, Riechers et al. (2013) report both the spread of homogeneous freezing temperatures and the mean $\mu$ and standard deviation $\sigma$ of droplet size. According to Eq. (3), the spread in the size distribution of water droplets will result in a spread in the fraction of frozen droplets because larger droplets have higher $T_{N_{\mathrm{c}}=1}\left(V, a_{\mathrm{w}}\right)$ (i.e., require less supercooling to freeze). Given the droplet size width, the distribution of the approximations $T_{N_{\mathrm{c}}=1}\left(V, a_{\mathrm{w}}\right)$ of droplets can be derived from Eq. (2). Given a Gaussian distribution of drop sizes, we estimate the fraction of drops that will freeze at a given temperature solely by assuming that the spread in freezing temperatures arises from the spread in droplet sizes based on Eq. (3). For example, we estimate $T_{N_{\mathrm{c}}=1}\left(V, a_{\mathrm{w}}\right)$ of the droplets with size of $\mu+3 \sigma(\sim$ the largest $0.15 \%$ of the drops) as the theoretical onset freezing temperature $T_{\mathrm{f}}^{\text {onset }}$, $T_{N_{\mathrm{c}}=1}\left(V, a_{\mathrm{w}}\right)$ of the droplets with size of $\mu+1.64 \sigma(\approx$ the largest $10 \%$ of the drops) as the theoretical estimates $T_{\mathrm{f}}^{10 \%}$, $T_{N_{\mathrm{c}}=1}\left(V, a_{\mathrm{w}}\right)$ of the droplets with mean size as the theoretical estimates $T_{\mathrm{f}}^{50 \%}, T_{N_{\mathrm{c}}=1}\left(V, a_{\mathrm{w}}\right)$ of the droplets with size of $\mu-1.64 \sigma(\approx$ the smallest $10 \%$ of the drops) as the theoretical estimates $T_{\mathrm{f}}^{90 \%}$, and $T_{N_{\mathrm{c}}=1}\left(V, a_{\mathrm{w}}\right)$ of the droplets with size of $\mu-3 \sigma(\approx$ the smallest $0.15 \%$ of the drops) as the theoretical estimates $T_{\mathrm{f}}^{\text {end }}$. The results presented in this section only use the value of $\sigma_{\mathrm{i} / \mathrm{w}, \mathrm{e}}$ from the TIP4P water model, which has the best agreement with the experimental data shown in Sect. 3.1 (Fig. 1).
There are five experimental results from Riechers et al. (2013), each with different $\mu$ and $\sigma$. The comparisons (Fig. 5 and Table 2) show that our estimates match the experimental data fairly well. The slope of the freezing fraction vs. temperature in the theoretical results is driven entirely by the reported spread in the size distribution of drops and matches fairly well with the observed slope, although across the experiments the theoretical slope is somewhat greater (observed values are shifted to the right of the blue curve at the higher temperatures but mostly to the left at the lower temperature), which might be attributable to the stochastic feature of the ice nucleation process. That said, the observational uncertainties in the experimental values of $T_{\text {onset }}$, $T_{10 \%}, T_{50 \%}$ and $T_{90 \%}$ more or less span the theoretical values derived from Eq. (2). Riechers et al. (2013) also reported that, during cooling, the majority of the droplets are frozen over a temperature interval of $0.84-0.98 \mathrm{~K}$, which is consistent with the range between the theoretical estimates $T_{\mathrm{f}}^{\text {onset }}$ and $T_{\mathrm{f}}^{\text {end }}$ derived here, namely $0.42-1.06 \mathrm{~K}$ from five different droplet size distributions, suggesting the spread in droplet size (i.e., a disperse distribution) may be an important factor governing the spread of the homogeneous freezing temperatures observed in a given fraction experiment.

The comparisons made in Sect. 3.1 to 3.2 shows that the distribution of the freezing temperatures among the data can mostly be explained by the dependence of $T_{N_{\mathrm{c}}=1}\left(V, a_{\mathrm{W}}\right)$ on $V$ and $a_{\mathrm{w}}$ for droplet diameter $>10 \mu \mathrm{m}$ and $a_{\mathrm{w}}>0.85$ without considering the dependence of homogeneous freezing temperature on $N_{\text {total_droplets }}$ and $\gamma_{\text {cooling }}$ in the calculations. It suggests that, in most of the practical experi- 
Table 2. Comparison between the experimental results of the fraction experiment from Riechers et al. (2013) and the theoretical estimates $T_{N_{\mathrm{c}}=1}$ derived here.

\begin{tabular}{|c|c|c|c|c|c|c|}
\hline \multirow{2}{*}{$\begin{array}{l}\text { Diameter } \\
\mu \pm \sigma\end{array}$} & \multicolumn{2}{|c|}{$96 \pm 11(\mu \mathrm{m})$} & \multicolumn{2}{|c|}{$85 \pm 6(\mu \mathrm{m})$} & \multicolumn{2}{|c|}{$82 \pm 8(\mu \mathrm{m})$} \\
\hline & $\begin{array}{r}\text { Experiment } \\
\text { values }(\mathrm{K})\end{array}$ & $T_{N_{\mathrm{c}}=1}(\mathrm{~K})$ & $\begin{array}{r}\text { Experiment } \\
\text { values }(\mathrm{K})\end{array}$ & $T_{N_{\mathrm{c}}=1}(\mathrm{~K})$ & $\begin{array}{r}\text { Experiment } \\
\text { values }(\mathrm{K})\end{array}$ & $T_{N_{\mathrm{c}}=1}(\mathrm{~K})$ \\
\hline$T_{\mathrm{f}}^{\text {onset }}$ & $237.91 \pm 0.2$ & 237.74 & $237.77 \pm 0.2$ & 237.53 & $237.63 \pm 0.2$ & 237.55 \\
\hline$T_{\mathrm{f}^{1}}^{10 \%}$ & $237.87 \pm 0.2$ & 237.59 & $237.76 \pm 0.2$ & 237.43 & $237.63 \pm 0.2$ & 237.42 \\
\hline$T_{\mathrm{f}}^{50 \%}$ & $237.4 \pm 0.3$ & 237.46 & $237.28 \pm 0.3$ & 237.34 & $237.13 \pm 0.3$ & 237.31 \\
\hline$T_{\mathrm{f}}^{90 \%}$ & $236.89 \pm 0.3$ & 237.31 & $236.93 \pm 0.3$ & 237.25 & $236.67 \pm 0.3$ & 237.18 \\
\hline$T_{\mathrm{f}}^{\mathrm{end}}$ & $\mathrm{NA}$ & 237.05 & NA & 237.11 & NA & 236.97 \\
\hline Diameter & $63 \pm 1$ & $(\mu \mathrm{m})$ & $53 \pm 6$ & $\mu \mathrm{m})$ & & \\
\hline$\mu \pm \sigma$ & $\begin{array}{r}\text { Experiment } \\
\text { values }(\mathrm{K})\end{array}$ & $T_{N_{\mathrm{c}}=1}(\mathrm{~K})$ & $\begin{array}{r}\text { Experiment } \\
\text { values }(\mathrm{K})\end{array}$ & $T_{N_{\mathrm{c}}=1}(\mathrm{~K})$ & & \\
\hline$T_{\mathrm{f}}^{\text {onset }}$ & $237.50 \pm 0.2$ & 237.43 & $237.44 \pm 0.2$ & 237.17 & & \\
\hline$T_{\mathrm{f}}^{10 \%}$ & $237.46 \pm 0.2$ & 237.23 & $237.40 \pm 0.2$ & 237.02 & & \\
\hline$T_{\mathrm{f}}^{50 \%}$ & $236.94 \pm 0.3$ & 237.05 & $236.94 \pm 0.3$ & 236.88 & & \\
\hline$T_{\mathrm{f}}^{90 \%}$ & $236.49 \pm 0.3$ & 236.83 & $236.55 \pm 0.3$ & 236.72 & & \\
\hline$T_{\mathrm{f}}^{\mathrm{e}}$ & NA & 236.4 & NA & 236.46 & & \\
\hline
\end{tabular}

ments and for most atmospheric conditions, the timescale of $\tau_{\text {residence }}$ is shorter than $\tau_{\text {meta_remove }}$ at the temperatures higher than $T_{N_{\mathrm{c}}=1}\left(V, a_{\mathrm{W}}\right)$ (i.e., $\tau_{\text {residence }}<\tau_{\text {meta_remove }}$, when $\left.T>T_{N_{\mathrm{c}}=1}\left(V, a_{\mathrm{w}}\right)\right)$, and when the temperature of the droplets is close to $T_{N_{\mathrm{c}}=1}\left(V, a_{\mathrm{W}}\right)$, the timescale of $\tau_{\text {meta_remove }}$ decreases strongly with temperature decreases and becomes shorter than $\tau_{\text {residence }}$ of the experiments (i.e., $\tau_{\text {residence }}>\tau_{\text {meta_remove }}$ when $\left.T<T_{N_{\mathrm{c}}=1}\left(V, a_{\mathrm{w}}\right)\right)$. This leads to the result that most of the homogeneous ice nucleation process can only be observed at temperatures close to $T_{N_{\mathrm{c}}=1}\left(V, a_{\mathrm{w}}\right)$ even though, in principle, droplets can be frozen at any temperature.

\section{Discussion}

As mentioned in Sect. 2, the observed freezing temperatures with $\gamma_{\text {cooling }} \sim 2.5 \mathrm{~K} \mathrm{~min}^{-1}$ reported in Murray et al. (2010) can be well described by $T_{N_{\mathrm{c}}=1}\left(V, a_{\mathrm{w}}\right)$, but there is a shift of 0.5 to $1 \mathrm{~K}$ in observed freezing temperatures when varying the cooling rate from 2.5 to $10 \mathrm{~K} \mathrm{~min}^{-1}$. One possibility is that the total freezing time $\tau_{\text {freezing }}$ needed to freeze a droplet at $T_{N_{\mathrm{c}}=1}\left(V, a_{\mathrm{w}}\right)$ is longer than the timescale of $\tau_{\text {residence }}$ when $\gamma_{\text {cooling }}$ is higher than $2.5 \mathrm{~K} \mathrm{~min}^{-1}$, which may be attributed to $\tau_{\text {meta_remove, }} \tau_{\text {formation }}$ or $\tau_{\text {growing }}$. Without considering the experimental uncertainty associated with the thermal equilibrium time $\tau_{\text {thermal }}$, these 0.5 to $1 \mathrm{~K}$ shifts correspond to 3 to $6 \mathrm{~s}$ shifts (for $\gamma_{\text {cooling }}=-10 \mathrm{~K} \mathrm{~min}^{-1}$ ), which may be partly caused by $\tau_{\text {formation }}+\tau_{\text {growing }}$. Bauerecker et al. (2008) (hereafter Ba08) explored an advanced method providing time series of water droplet temperature during the entire cooling and freezing process (from supercooled wa- ter to completely freezing) using an infrared camera. The results of $\mathrm{Ba} 08$ showed for the droplet sized $3 \mathrm{~mm}$ (diameter) that $\tau_{\text {growing }}$ is around $20 \mathrm{~s}$ and $\tau_{\text {thermal }}$ is around $60 \mathrm{~s}$. The droplet used in $\mathrm{Ba} 08$ is much larger than the size normally used in the freezing experiments because of the limitation of IR camera sensitivity. If $\tau_{\text {growing linearly depends }}$ on drop radius, we may expect it to be several tenths of a second for the drops sized $10-100 \mu \mathrm{m}$ in diameter. We suggest that the infrared camera technique should be used more widely in the future experimental studies of ice nucleation with smaller droplets, which can add significant insights into the time dependence study of ice nucleation, and clarify the importance of $\tau_{\text {meta_remove }}, \tau_{\text {formation }}$ and $\tau_{\text {growing }}$ observed in the experiments. On the other hand, Koop et al. (1998) suggested that mass transport of water can take place between the frozen ice particles and supercooled droplets when the cooling rate is smaller than about $2 \mathrm{~K} \mathrm{~min}^{-1}$, but if the cooling rate is too large, it can cause an offset between the measured temperature and the actual temperature of the drops, which can cause a bias in the observed freezing temperatures. Therefore, we suggest that in future experimental studies, in order to precisely measure $\frac{\partial T_{\mathrm{f}}}{\partial \gamma_{\text {cooling }}}$, potential biases at high cooling rate and the shift caused by $\tau_{\text {formation }}+\tau_{\text {growing }}$ should be better constrained. Since Koop et al. (1998) and Murray et al. (2010) showed different dependencies of ho-

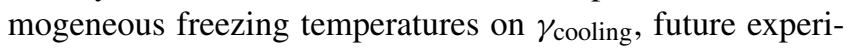
ments should reexamine and perform the same experiments for $\gamma_{\text {cooling }}>2.5 \mathrm{~K} \mathrm{~min}^{-1}$. The results shown in Figs. 1 and 4 suggest that the time consideration may be more important when droplet volume and water activity are low where the experimental data show considerable inconsistency (i.e., 
$a_{\mathrm{w}}<0.85$ and $d<10 \mu \mathrm{m}$ ), and future experiments are suggested to emphasize these droplet size and water activity ranges.

\section{Summary}

The limitation of our method proposed here is that the time dependence and the stochastic feature of homogeneous freezing temperature cannot be considered because the Boltzmann distribution applied here is a average distribution and does not provide any information regarding time. Combining the well-known Boltzmann distribution function for the mean number of critical embryos $N_{\mathrm{c} \_ \text {mean }}\left(V, a_{\mathrm{w}}, T\right)$ and their formation energy $\Delta F_{\mathrm{c}}\left(T, a_{\mathrm{w}}\right)$ from CNT formulae, $T_{N_{\mathrm{c}}=1}\left(V, a_{\mathrm{w}}\right)$ is derived as a function of volume and water activity of water droplets. With the comparisons made in Sect. 3.1 to 3.2, it can be summarized that, under most atmospheric conditions, homogeneous freezing temperatures can be well described by the new approximation $T_{N_{\mathrm{c}}=1}\left(V, a_{\mathrm{w}}\right)$ proposed here without considering information of the applied cooling rate (i.e., time dependence) and the number of droplets used in the experiment (i.e., stochastic feature) for $d>10 \mu \mathrm{m}$ and $a_{\mathrm{w}}>0.85$. Future experimental study is suggested to focus on the homogeneous freezing process of droplets with high solute concentration $\left(a_{\mathrm{w}}<0.85\right)$ and small volume $(d<10 \mu \mathrm{m})$. The experimental spread in homogeneous freezing temperatures of water droplets may be partly explained by the size distribution of droplets used in the experiments. The advantage of our approximation in the cloud modeling is that the "temperature history" of droplets is not required to calculate the homogeneous freezing temperature as it is when using the ice nucleation rate (i.e., Eqs. 7-71 in Pruppacher and Klett, 1997). When using the ice nucleation rate $J(T(t))$, the complete temperature history of droplets is needed to calculate the integration of $J(T(t))$ with respect to time in order to consider the time dependence and the stochastic feature, which can introduce considerable complexity in cloud modeling. However, based on the experimental studies of homogeneous freezing temperature collected and discussed in our study, we suggest that, in most of the practical experiments and realistic atmospheric conditions (i.e., $\gamma_{\text {cooling }}<20 \mathrm{~K} \mathrm{~min}^{-1}$ ), the time dependence and the stochastic feature of homogeneous freezing temperature may be a secondary factor compared to the effect of volume and water activity for droplet diameter $>10 \mu \mathrm{m}$ and $a_{\mathrm{w}}>0.85$. The approximation proposed here is relatively simple to implement into cloud models and may improve the representation of homogeneous ice nucleation in the atmosphere.

Acknowledgements. The authors gratefully appreciate helpful discussions with Marcia Baker, Daniel Cziczo and Sarvesh Garimella, who provided important insight and guidance for this study. Two anonymous reviewers are thanked for providing important feedback that helped to improve the paper. The authors thank Thomas Koop for his help in supplying the data in Fig. 4.

Edited by: A. Nenes

\section{References}

Abbatt, J. P., Benz, S., Cziczo, D. J., Kanji, Z., Lohmann, U., and Mohler, O.: Solid ammonium sulfate aerosols as ice nuclei: a pathway for cirrus cloud formation, Science, 313, 1770-1773, 2006.

Alpert, P. A., Aller, J. Y., and Knopf, D. A.: Initiation of the ice phase by marine biogenic surfaces in supersaturated gas and supercooled aqueous phases, Phys. Chem. Chem. Phys., 13, 19882-19894, 2011.

Baker, M. and Baker, M.: A new look at homogeneous freezing of water, Geophys. Res. Lett., 31, L19102, doi:10.1029/2004GL020483, 2004.

Barahona, D.: Analysis of the effect of water activity on ice formation using a new thermodynamic framework, Atmos. Chem. Phys., 14, 7665-7680, doi:10.5194/acp-14-7665-2014, 2014.

Bauerecker, S., Ulbig, P., Buch, V., Vrbka, L., and Jungwirth, P.: Monitoring ice nucleation in pure and salty water via high-speed imaging and computer simulations, J. Phys. Chem. C, 112, 76317636, 2008.

Benet, J., MacDowell, L. G., and Sanz, E.: A study of the ice-water interface using the TIP4P/2005 water model, Phys. Chem. Chem. Phys., 16, 22159-22166, 2014.

Bertram, A. K., Koop, T., Molina, L. T., and Molina, M. J.: Ice formation in $\left(\mathrm{NH}_{4}\right) 2 \mathrm{SO}_{4}-\mathrm{H}_{2} \mathrm{O}$ particles, J. Phys. Chem. A, 104, 584-588, 2000.

Bigg, E. K.: The supercooling of water, P. Phys. Soc. B, 66, 688694, doi:10.1088/0370-1301/66/8/309, 1953.

Black, S.: Simulating nucleation of molecular solids, P. Roy. Soc. A-Math. Phy., 463, 2799-2811, 2007.

Bourne, J. and Davey, R.: The role of solvent-solute interactions in determining crystal growth mechanisms from solution: I. The surface entropy factor, J. Cryst. Growth, 36, 278-286, 1976.

Brewer, A. W. and Palmer, H. P.: Freezing of supercooled water, P. Phys. Soc. B, 64, 765-773, 1951.

Broto, F. and Clausse, D.: A study of the freezing of supercooled water dispersed within emulsions by differential scanning calorimetry, J. Phys. C Solid State, 9, 4251, doi:10.1088/00223719/9/23/009, 1976.

Carte, A.: The freezing of water droplets, P. Phys. Soc. B, 69, 10281037, 1956.

Cziczo, D. and Abbatt, J.: Deliquescence, efflorescence, and supercooling of ammonium sulfate aerosols at low temperature: Implications for cirrus cloud formation and aerosol phase in the atmosphere, J. Geophys. Res.-Atmos. (1984-2012), 104, 1378113790, 1999.

Dufour, L. and Defay, R.: Thermodynamics of clouds, Academic Press, New York, USA, 1963.

Duft, D. and Leisner, T.: Laboratory evidence for volumedominated nucleation of ice in supercooled water microdroplets, Atmos. Chem. Phys., 4, 1997-2000, doi:10.5194/acp-4-19972004, 2004. 
Earle, M. E., Kuhn, T., Khalizov, A. F., and Sloan, J. J.: Volume nucleation rates for homogeneous freezing in supercooled water microdroplets: results from a combined experimental and modelling approach, Atmos. Chem. Phys., 10, 7945-7961, doi:10.5194/acp-10-7945-2010, 2010.

Espinosa, J., Sanz, E., Valeriani, C., and Vega, C.: Homogeneous ice nucleation evaluated for several water models, J. Chem. Phys., 141, 18C529, doi:10.1063/1.4897524, 2014.

Hoffer, T. E.: A laboratory investigation of droplet freezing, J. Meteorol., 18, 766-778, 1961.

Hu, Y., Rodier, S., Xu, K., Sun, W., Huang, J., Lin, B., Zhai, P., and Josset, D.: Occurrence, liquid water content, and fraction of supercooled water clouds from combined CALIOP/IIR/MODIS measurements, J. Geophys. Res.-Atmos., 115, D00H34, doi:10.1029/2009JD012384, 2010.

Ickes, L., Welti, A., Hoose, C., and Lohmann, U.: Classical nucleation theory of homogeneous freezing of water: thermodynamic and kinetic parameters, Phys. Chem. Chem. Phys., 17, 55145537, 2015.

Jones, D. and Chadwick, G.: Experimental measurement of solidliquid interfacial energies: The ice-water-sodium chloride system, J. Cryst. Growth, 11, 260-264, 1971.

Kay, J. E., Tsemekhman, V., Larson, B., Baker, M., and Swanson, B.: Comment on evidence for surface-initiated homogeneous nucleation, Atmos. Chem. Phys., 3, 1439-1443, doi:10.5194/acp3-1439-2003, 2003.

Khvorostyanov, V. I. and Curry, J. A.: Critical humidities of homogeneous and heterogeneous ice nucleation: Inferences from extended classical nucleation theory, J. Geophys. Res.-Atmos., 114, D04207, doi:10.1029/2008JD011197, 2009.

Knopf, D. A. and Lopez, M. D.: Homogeneous ice freezing temperatures and ice nucleation rates of aqueous ammonium sulfate and aqueous levoglucosan particles for relevant atmospheric conditions, Phys. Chem. Chem. Phys., 11, 8056-8068, 2009.

Knopf, D. A. and Rigg, Y. J.: Homogeneous ice nucleation from aqueous inorganic/organic particles representative of biomass burning: Water activity, freezing temperatures, nucleation rates, J. Phys. Chem. A, 115, 762-773, 2011.

Koop, T., Ng, H. P., Molina, L. T., and Molina, M. J.: A new optical technique to study aerosol phase transitions: The nucleation of ice from $\mathrm{H}_{2} \mathrm{SO}_{4}$ aerosols, J. Phys. Chem. A, 102, 8924-8931, 1998.

Koop, T., Luo, B., Tsias, A., and Peter, T.: Water activity as the determinant for homogeneous ice nucleation in aqueous solutions, Nature, 406, 611-614, 2000.

Kuhns, I. and Mason, B.: The supercooling and freezing of small water droplets falling in air and other gases, P. Roy. Soc. Lond. A Mat., 302, 437-452, 1968.

Landau, L. and Lifshitz, E.: Statistical Physics: V. 5: Course of Theoretical Physics, Pergamon Press, New York, USA, 1969.

Langham, E. and Mason, B.: The heterogeneous and homogeneous nucleation of supercooled water, P. Roy. Soc. Lond. A Mat., 247, 493-504, 1958.
Larson, B. H. and Swanson, B. D.: Experimental investigation of the homogeneous freezing of aqueous ammonium sulfate droplets, J. Phys. Chem. A, 110, 1907-1916, 2006.

McDonald, J. E.: Homogeneous nucleation of supercooled water drops, J. Meteorol., 10, 416-433, 1953.

Mossop, S.: The freezing of supercooled water, P. Phys. Soc. Lond. B, 68, 193-208, doi:10.1088/0370-1301/68/4/301, 1955.

Murphy, D. and Koop, T.: Review of the vapour pressures of ice and supercooled water for atmospheric applications, Q. J. Roy. Meteor. Soc., 131, 1539-1565, 2005.

Murray, B., Broadley, S., Wilson, T., Bull, S., Wills, R., Christenson, H., and Murray, E.: Kinetics of the homogeneous freezing of water, Phys. Chem. Chem. Phys., 12, 10380-10387, 2010.

Niedermeier, D., Shaw, R. A., Hartmann, S., Wex, H., Clauss, T., Voigtländer, J., and Stratmann, F.: Heterogeneous ice nucleation: exploring the transition from stochastic to singular freezing behavior, Atmos. Chem. Phys., 11, 8767-8775, doi:10.5194/acp11-8767-2011, 2011.

Pound, G. M., Madonna, L., and Peake, S.: Critical supercooling of pure water droplets by a new microscopic technique, J. Colloid Sci., 8, 187-193, 1953.

Prenni, A. J., Wise, M. E., Brooks, S. D., and Tolbert, M. A.: Ice nucleation in sulfuric acid and ammonium sulfate particles, $\mathrm{J}$. Geophys. Res.-Atmos. (1984-2012), 106, 3037-3044, 2001.

Pruppacher, H.: A new look at homogeneous ice nucleation in supercooled water drops, J. Atmos. Sci., 52, 1924-1933, 1995.

Pruppacher, H. and Klett, J.: Microphysics of clouds and precipitation, 2nd Edn., Kluwer Academic Publishers, Boston, MA, USA, 1997.

Riechers, B., Wittbracht, F., Hütten, A., and Koop, T.: The homogeneous ice nucleation rate of water droplets produced in a microfluidic device and the role of temperature uncertainty, Phys. Chem. Chem. Phys., 15, 5873-5887, 2013.

Rosenfeld, D. and Woodley, W. L.: Deep Convective Clouds with Sustained Supercooled Liquid Water down to $-37.5^{\circ} \mathrm{C}$, Nature, 405, 440-442, 2000.

Sadovskii, M. V.: Statistical Physics, De Gruyter Studies in Mathematical Physics, Berlin, Germany, 2012.

Spaepen, F.: A structural model for the solid-liquid interface in monatomic systems, Acta Metallurgica, 23, 729-743, 1975.

Stan, C. A., Schneider, G. F., Shevkoplyas, S. S., Hashimoto, M., Ibanescu, M., Wiley, B. J., and Whitesides, G. M.: A microfluidic apparatus for the study of ice nucleation in supercooled water drops, Lab Chip, 9, 2293-2305, 2009.

Vali, G.: Ice Nucleation-Theory: A Tutorial, presented at the NCAR/ASP 1999 Summer Colloquium, 14-25 June 1999, Boulder, Colorado, USA, 1999 (unpublished).

Zobrist, B., Koop, T., Luo, B., Marcolli, C., and Peter, T.: Heterogeneous ice nucleation rate coefficient of water droplets coated by a nonadecanol monolayer, J. Phys. Chem. C, 111, 2149-2155, 2007. 